\title{
The Modern upper crust is altered and the Archean upper crust was Andesitic: Results from a novel analysis of major element data
}

\author{
AlEX LiPP $^{1 *}$, Oliver SHORTTLE ${ }^{2,3}$, FrANK SYVRET $^{4}$, \\ GARETH G. ROBERTS ${ }^{1}$, SEDIMENTARY GEOCHEMISTRY AND \\ PALEOENVIRONMENTS PROJECT ${ }^{6}$ \\ ${ }^{1}$ Department of Earth Sciences \& Engineering, Imperial College \\ London (*correspondence: a.lipp18@imperial.ac.uk) \\ ${ }^{2}$ Institute of Astronomy, University of Cambridge \\ ${ }^{3}$ Department of Earth Sciences, University of Cambridge \\ ${ }^{4}$ Bullard Laboratories, University of Cambridge \\ ${ }^{6}$ sgp.stanford.edu
}

The elemental composition of sediments is set by their protolith and modified by chemical weathering, sorting and numerous other processes. Unravelling these different effects to gain useful information about Earth's surface is a challenge for sedimentary geochemical analysis. This issue is particularly acute due to ongoing controversy over the composition of the Archean continental crust as reconstructed from sedimentary rocks [1,2].

We present a novel method [3] to separate the effects of chemical weathering and protolith composition from the major element composition of sediments. Initially, Principal Component Analysis is used to simplify a dataset of sedimentary compositions. This reveals that a $2 \mathrm{D}$ vector addition model considering just weathering and protolith composition can be used to describe most compositional diversity in sediments. For a given sediment the model can be inverted to provide the protolith composition and the intensity of weathering experienced.

We apply this new method to the major element composition of the upper continental crust (UCC). We find that the composition of UCC can only be explained if it has experienced chemical weathering relative to pristine igneous rocks. However, the magnitude of this alteration is significantly less than expected if present day weathering rates are extrapolated over the total age of the crust. This discrepancy can be resolved by assuming a crust-to-mantle recycling rate of $1.33 \pm 0.89 \times 10^{13} \mathrm{~kg} \mathrm{yr}^{-1}$.

We subsequently apply our analytical method to a dataset of ancient sedimentary rocks to reconstruct the changing average composition of the UCC. We find that prior to $2.5 \mathrm{Ga}$ the UCC was Andesitic with $61 \mathrm{wt} \% \mathrm{SiO}_{2}$. By $2.0 \mathrm{Ga}$ it had evolved into a Dacitic composition close to the Modern UCC. Despite this secular trend the crust was strongly compositionally heterogeneous at any one time.

[1] Tang et al. (2016) Science 351, 372-375. [2] Greber \& Dauphas (2019) Geochim. Cosmochim. Acta 255, 247-264. [3] Lipp et al. (in press) Geochemistry, Geophys. Geosystems. 